\title{
PENGGUNAAN BAHASA DAERAH GENERASI MUDA PROVINSI MALUKU UTARA DAN PAPUA BARAT
}

The Use of Vernacular of Youth Generational of North Maluku and West Papua Province

\author{
Buha Aritonang \\ Badan Pengembangan dan Pembinaan Bahasa \\ buhaaritonang@yahoo.co.id
}

Naskah Diterima Tanggal 2 Oktober 2019-Direvisi Akhir Tanggal 24 Oktober 2020_Disetujui Tanggal 2 Desember 2020 doi: https://doi.org/10.26499/rnh.v9i2.2936

\begin{abstract}
Abstrak
Penggunaan bahasa daerah di kalangan generasi muda ketika menulis surat dan short massage service (SMS)/ whatsapp (WA) dalam ranah keluarga menarik untuk dikaji. Dalam tulisan ini kajian dibatasi pada masalah penggunaan bahasa daerah di kalangan generasi muda, khususnya generasi muda Maluku Utara dan Papua Barat dalam ranah keluarga ketika mereka menulis surat dan SMS/WA kepada mitra tutur. Tujuan penelitian mendeskripsikan kategori penggunaan bahasa daerah generasi muda Maluku Utara dan Papua Barat ketika menulis surat dan SMS/WA dengan mitra tuturnya. Metode penelitian ini bersifat deskriptif kualitatif yang datanya dikumpulkan dengan metode penyebaran kuesioner. Hasil analisis menunjukkan bahwa generasi muda Maluku Utara menulis surat kepada mitra tutur (orang tua, paman/tante/bibi, kakek/nenek, saudara (kakak/adik), dan famili jauh) dengan bahasa daerah melalui surat tergolong sangat tidak baik dan melalui SMS/WA tergolong tidak baik. Generasi muda Papua Barat Utara menulis surat kepada mitra tutur (orang tua, paman/tante/bibi, kakek/nenek, saudara (kakak/adik), dan famili jauh) dengan bahasa daerah, baik melalui surat maupun SMS/WA tergolong tidak baik.
\end{abstract}

Kata-kata Kunci: generasi muda, penggunaan bahasa, short massage service, whatsapp

\begin{abstract}
The use of vernacular among the younger generation when writing letters and short massage service (SMS)/ whatsapp (WA) in the family domain is interesting to study. In this paper the study is limited to the problem of using vernacular among the younger generation, especially the younger generation of North Maluku and West Papua is in the family domain when they write letters and SMS/WA messages to speech partners. The objective of this research is to describe the category of language use of the young generation of North Maluku and West Papua when writing letters and SMS/WA with their speech partners. This research method is descriptive qualitative in which the data. The results of the analysis showed that the young generation of North Maluku wrote letters to speech partners (parents, uncle/aunt/aunt, grandparents, siblings (brother/sister), and distant relatives) in vernacular through classified letters. very bad and through SMS/WA classified as not good the young generation of North West Papua wrote a letter to speech partners (parents, uncle/aunt/aunt, grandfather/grandmother, siblings (brother/sister), and distant family) using vernacular, either through letters or SMS/WA are classified as not good.
\end{abstract}

Keywords: Young generation, language use, short massage service, whatsapp

How to Cite: Aritonang, Buha. (2020). Penggunaan Bahasa Daerah Generasi Muda Provinsi Maluku Utara dan Papua Barat. Ranah: Jurnal Kajian Bahasa. 9(2). 160-177. doi: https://doi.org/10.26499/rnh.v9i2.2936 


\section{PENDAHULUAN}

Chaer (201: 212) menjelaskan bahasa daerah atau bahasa ibu adalah bahasa yang dapat digunakan dalam komunikasi intrasuku. Keberadaannya di wilayah tutur Indonesia masih tetap diaspresiasi walaupun bersinggungan dengan bahasa Indonesia sebagai bahasa yang digunakan oleh penutur intrabangsa dalam situasi resmi dan bahasa asing sebagai bahasa yang berasal dari bangsa lain.

Bahasa daerah dapat dinyatakan sebagai bagian yang tidak terpisahkan dari kebudayaan yang hidup dan berkembang sesuai dengan kebutuhan masyarakat penuturnya. Sekarang ini, sebagian pemerhati bahasa mencemaskan banyaknya bahasa daerah di Indonesia yang diprediksi akan punah jika terjadi pembiaran oleh pihak yang berkompeten, termasuk pemilik bahasa daerah yang kurang respek terhadap warisan budaya yang seharusnya tetap dipelihara. Bahasa daerah merupakan refleksi dan identitas sebuah budaya yang paling kokoh dan instrumen pengikat yang sangat kuat untuk mempertahankan eksistensi suatu budaya etnik tertentu. Oleh karena itu, keterwujudan pelestarian bahasa daerah di Indonesia harus didukung dengan penumbuhan kesadaran pemeliharaan oleh setiap penuturnya. Penutur harus mengunakan bahasa daerahnya dalam aktivitas kehidupan dan kesempatan tertentu untuk mengendalikan budaya yang dimiliki agar tidak punah.

Objek kajian bahasa daerah yang dilakukan oleh para linguis di Provinsi Maluku Utara dan Papua Barat tergolong cukup banyak. Contoh kajian bahasa daerah di Provinsi Maluku Utara adalah kajian bahasa Ternate yang dikaitkan dengan sastra lisan dan acara ritual keagamaan (Karim dan Hasim, 2018: 1), bahasa Ibu dan bahasa Kao di Halmahera Utara diangkat sebagai topik bahasan dalam hubungan keterancanaman bahasa daerah (Ibrahim, 2011: 41), dan lain-lain. Bahasa daerah di Provinsi Papua Barat pun tidak lepas dari perhatian para linguis, seperti deskripsi fonologi bahasa Abun di Kabupaten Tambrauw yang termasuk dalam kelompok bahasa non-Austronesia (Maturbongs dan Asmabuasappe, 2016); cara menghitung bahasa Miyah yang dimulai dari angka $1-5$, lalu angka 6 dipakai sebagai dasar untuk menghitung angka dari 6-10, selanjutnya angka 10 dipakai sebagai dasar untuk menghitung angka dari 10-15 (Baru, 2018); dan lain-lain.

Sementara itu, bahasa-bahasa daerah di wilayah Provinsi Maluku Utara dan Papua Barat berkaitan dengan masyarakat tutur bahasa, khususnya kelompok penutur generasi muda yang multietnik dan memiliki multibahasa daerah. Kelompok penutur generasi muda di wilayah ini merupakan generasi muda lokal dan pendatang. Penutur generasi muda ini berstatus pelajar, mahasiswa, dan karyawan. Aktivitas mereka sehari-hari pun, khususnya dalam ranah rumah 
tangga, tidak lepas dari aktivias berkomunikasi yang menggunakan bahasa daerah masingmasing sebagai lambang indentitas keetnikan. Bertitik tolak dari hal ini, timbullah asumsi bahwa penguasaan bahasa daerah di kalangan muda Provinsi Maluku Utara dan Papua Barat dalam ranah keluarga masih digunakan ketika menulis surat atau SMS/WA dengan mitra tutur.

Kajian tentang menulis dan SMS/WA sudah pernah dilakukan sebelumnya oleh para linguis. Fitur bahasa SMS para siswa berupa pesan verbal, yang terdiri atas fonem, morfem, leksikon, frasa, dan kalimat atau pesan nonverbal yang berupa emotisi (tanda rasa), telah dilakukan oleh Sriningsih (2016: 1). Sriningsih mendeskripsikan fitur linguistik dan nonlinguistik penggunaan bahasa SMS pada siswa SMPN 4 Mataram dan implikasinya terhadap pembelajaran bahasa Indonesia di sekolah. Selain itu, penggunaan whatsapp (WA) untuk peningkatan keterampilan menulis siswa telah dilakukan oleh Widiyanti dan Harunasari (2019: 7). Berdasarkan kajian Widiyanti dan Harunasari, disimpulkan bahwa media whatsapp (WA) cocok untuk memfasilitasi siswa dalam meningkatkan keterampilan menulis mereka.

Berdasarkan kedua kajian tersebut, SMS dan WA dapat berkaitan dengan kajian linguistik. Dengan demikian, keduanya dapat dikaitkan juga dengan penggunaan bahasa daerah dalam ranah keluaga ketika digunakan antarpetutur. Seperti telah dinyatakan sebelumnya, pelestarian bahasa daerah sebagai aset kebudayaan perlu untuk dikendalikan dari aspek kepunahannya. Sehubungan dengan hal itu, salah satu hal yang dilakukan untuk melihat kondisi pelestarian bahasa daerah di Provinsi Maluku Utara dan Papua Barat ialah kondisi pemakaiannya di kalangan generasi muda dalam ranah keluarga khususnya ketika mereka menulis surat dan SMS/WA kepada mitra tutur, seperti kepada saudara (kakak/adik), famili, orang tua, paman/tante/bibi, atau kakek/nenek. Dengan demikian, penelitian ini bertujuan untuk mendeskripsikan penggunaan bahasa daerah generasi muda Provinsi Maluku Utara dan Provinsi Papua Barat dalam ranah keluarga ketika generasi muda menulis surat dan SMS/WA kepada mitra tutur.

\section{LANDASAN TEORI}

Teori yang terkait dengan penelitian ini adalah teori sosiolinguistik. Fishman (1972) dalam Chaer dan Agustina (2004: 3) mengemukakan bahwa sosiolinguistik adalah kajian tentang ciri khas variasi bahasa, fungsi variasi bahasa, dan pengunaan bahasa karena ketiga unsur ini berinteraksi dalam dan saling mengubah satu sama lain dalam satu masyarakat tutur, identitas sosial dari penutur, lingkungan sosial tempat peristiwa tutur terjadi, serta pada hakikatnya mengkaji hubungan bahasa dan masyarakat dengan mengaitkan dua bidang yang 
dikaji secara terpisah, yaitu struktur formal bahasa oleh linguistik dan struktur masyarakat oleh sosiologi. Sosiolinguistik menurut Kridalaksana (2009: 1) adalah cabang linguistik yang mempelajari hubungan dan saling pengaruh antarperilaku bahasa dan perilaku sosial. Chaer dan Agustina (2010: 7) menyatakan bahwa sosiolinguistik menjelaskan bagaimana menggunakan bahasa dalam aspek atau segi sosial tertentu. Sementara itu, Wijana dan Rohmadi (2013: 7) berpendapat bahwa sosiolinguistik adalah tingkatan variasi dan ragam linguistik. Wardhaugh (2006: 4) menjelaskan bahwa sosiolinguistik adalah cabang linguistik yang memandang atau menempatkan kedudukan bahasa dalam hubungannya dengan pemakai bahasa di dalam masyarakat karena dalam kehidupan bermasyarakat manusia tidak lagi sebagai individu, tetapi sebagai masyarakat.

Berkaitan dengan teori tersebut, dapat dijelaskan lebih lanjut bahwa pemakaian bahasa sebagai aspek tutur relatif berubah-ubah sesuai dengan perubahan unsur-unsur dalam konteks sosial budaya. Tiga hal yang berkaitan dengan hal itu adalah latar dan suasana tutur (the setting and scene), peserta tutur (the participants), dan topik tutur (act sequence) (Dell Hymes dalam Wardhaugh (1986: 238--239). Ketiga hal itu relevan diungkapkan dalam pemakaian bahasa daerah generasi muda Provinsi Maluku Utara dan Papua Barat.

Sementara itu, bahasa daerah terkait dengan pemakaian bahasa. Khotimah (2012) dalam Nurjannah dan Alfa Mitri Suhara (2019: 257) menyatakan bahwa bahasa daerah merupakan suatu penuturan bahasa dalam suatu wilayah di sebuah negara kebangsaan, seperti pada suatu negara bagian federal, provinsi, daerah kecil, atau wilayah yang lebih luas. Bahasa daerah pun tentu saja digunakan berbagai ranah. Menurut Fishman dalam Sumarsono (2007: 14), ranah merupakan konstelasi antara lokasi, topik, dan partisipan. Salah ranah menurut Sumarsono (2007: 197) adalah ranah keluarga (family domain) yang di dalamnya terkandung generasi muda. Auguste Comte, sang pelopor sosiologi modern, dalam Sumolang (2013: 5) menyatakan bahwa generasi adalah jangka waktu kehidupan sosial manusia yang didasarkan pada dorongan keterikatan pada pokok-pokok pikiran yang asasi. Dengan dasar itu, timbulah sebutan generasi muda. Menurut Sumolang (2013: 7), generasi muda adalah peralihan seseorang dari masa kanak-kanak menuju masa remaja atau muda dengan disertai perkembangan fisik dan nonfisik (jasmani, emosi, pola pikirannya dan sebagainya).

Sehungan dengan keterampilan berbahasa, kreativitas menulis merupakan salah satu bentuk keahlian yang harus dikuasai dalam berbahasa. Melalui menulis seseorang bisa menyampaikan ide atau gagasannya dalam bentuk tulisan (Amelia, 2016: 37). Surat dalam bentuk kertas merupakan salah satu diantaranya. Selain dengan surat, komunikasi melalui 
tulisan short massage service (SMS) atau whatsapp (WA) dapat menyampaikan pesan dalam bentuk teks tulisan singkat.

\section{METODE PENELITIAN}

Objek penelitian ini adalah generasi muda di (1) Kota Ternate dan Kabupaten Tidore Kepulauan, Provinsi Maluku Utara yang dilaksanakan pada bulan Januari-Desember 2018 dan (2) Kota Manokwari, Provinsi Papua Barat yang dilaksanakan pada bulan JanuariDesember 2019. Populasi penelitian dibatasi pada generasi muda Provinsi Maluku Utara dan Papua Barat. Sampel penelitian di Provinsi Maluku Utara adalah siswa sekolah menengah atas di Kabupaten Tidore Kepulauan, mahasiswa di Kota Tidore, dan karyawan di Kabupaten Tidore dan di Provinsi Papua Barat adalah siswa sekolah menengah atas, mahasiswa, dan karyawan di Kabupaten Manokwati. Pendekatan penelitian menggunakan pendekatan sosiolinguistik. Metode penelitian dikembangkan berdasarkan metode penelitian kuantitatif tentang penggunaan bahasa daerah dalam ranah kebahasaan yang mendeskripsikan penggunaan bahasa daerah dalan ranah keluarga ketika generasasi muda Provinsi Maluku Utara dan Papua Barat menulis surat dan SMS/WA kepada mitra tutur.

Jenis data penelitian ini adalah data primer. Data bersumber dari hasil penyebaran kuesioner (angket) kepada 160 generasi muda Provinsi Maluku Utara dan 120 generasi muda Provinsi Papua Barat. Sampel generasi muda ini terdiri atas (1) 40 siswa sekolah menengah atas Provinsi Maluku Utara dan 53 Papua Barat, (2) 40 mahasiswa Provinsi Maluku Utara dan 53 Papua Barat, dan (3) 40 karyawan Provinsi Maluku Utara dan 54 Papua Barat. Untuk medapatkan data digunalan teknik kuesioner (angket) dengan 10 item pernyataan yang berkaitan dengan penggunaan bahasa daerah dalam ranah keluarga ketika menulis surat dan SMS/WA kepada mitra tutur. Teknik pengumpulan data menggunakan kuesioner dengan ketentuan setiap generasi muda diminta untuk menjawab pertanyaan tentang penggunaan bahasa daerah dalam ranah keluarga ketika menulis surat dan SMS/WA dalam isian kuesioner. Pengolahan data menggunakan analisis penghitungan persentase mengikuti pola penghitungan Muhajir dalam Damanik (2009: 17). Data dalam penelitian ini disusun dalam bentuk tabel. Skala pengukuran menggunakan skala nominal karena skala ini merupakan sebatas label yang diberikan terhadap karakteristik responden dan pilihan jawaban.

Data dianalisis secara deskriptif kuantitatif dengan menggunakan rumus yang dikembangkan oleh Sudjino (2012: 43) dengan pola perhitungan statistik dalam bentuk persentase. Rumusnya adalah sebagai berikut. 


$$
P=\frac{F}{N} x 100 \% \quad \text { Keterangan: } \mathrm{P}=\text { angka persentase; } \mathrm{F}=\text { frekuensi yang sedang dicari persentasenya; dan } \mathrm{N}=\text { number of cases } \text { (jumlah }
$$
freluensi)

Skala pengunaan bahasa daerah dalam ranah kebahasaan dianalisis dengan menerapkan analisis data skor rata-rata berbobot (Durianto, 2003) dengan acuan rumus berikut.

$$
x=\frac{\sum f i . w i}{\sum f i} \text { Keterangan: } \mathrm{X}=\text { rata-rata berbobot; } f i=\text { frekuensi; } \Sigma f i=\text { bobot }
$$

Setiap jawaban responden dari item pernyataan diberi bobot dengan cara menghitung skor, yaitu menjumlahkah seluruh hasil kali nilai masing-masing bobotnya dibagi dengan jumlah total frekuensi. Setelah itu, digunakan rentang skala penilaian untuk menentukan posisi tanggapan responden dengan menggunakan nilai skor setiap variabel. Bobot alternatif jawaban yang terbentuk dari teknik skala peringkat terdiri atas kisaran $0-5$ yang menggambarkan posisi yang sangat negatif ke posisi yang positif. Selanjutnya, dihitung rentang skala dengan rumus berikut.

$$
R s=\frac{R(\text { bobot })}{M} \quad \text { Keterangan: } \mathrm{R}(\text { bobot })=\text { bobot terbesar }(\text { maksimal })-\text { bobot terkecil }(\text { minimal }) ; \mathrm{M}=\text { jumlah kategori bobot }
$$

Rentang skala Likert yang digunakan dalam penelitian ini adalah 1 hingga 5 sehingga rentang skala penilaian yang didapat melalui rumus tersebut adalah 0,80 dari perhitungan $R s=\frac{5-1}{5}=0,80$. Hasil perhitungan itu diterapkan dalam skala Likert untuk menunjukkan posisi rentang skala dan interpretasinya, yaitu sebagai berikut.

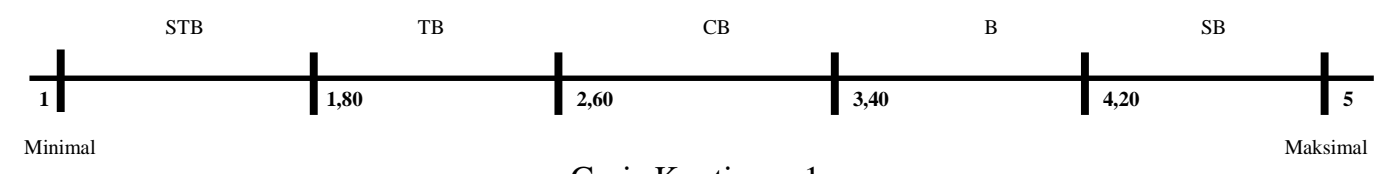

Garis Kontinum 1

Posisi dan Interpretasi Rentang Skala Likert

\section{Keterangan:}

$\mathrm{STB}=$ sangat tidak baik; $\mathrm{TB}=$ tidak baik; $\mathrm{CB}=$ cukup baik; $\mathrm{B}=\mathrm{bBaik} ; \mathrm{SB}=$ sangat baik

Setiawati, et al., (2013: 4) menambahkan bahwa skala Likert atau summated rating scale merupakan skala yang mengukur kesetujuan atau ketidaksetujuan seseorang terhadap serangkaian pernyataan berkaitan dengan keyakinan atau perilaku mengenai suatu objek tertentu. Artinya, untuk mengetahui secara keseluruhan persepsi masyarakat terhadap sesuatu hal dinyatakan dalam bentuk tinjauan kontinum sehingga dapat diketahui berapa besar persepsi masyarakat terhadap sesuatu hal itu apakah terletak pada kategori sangat tidak baik, tidak baik, cukup baik, baik, atau sangat baik. Untuk menentukannya, harus diketahui skor total sesuatu yang akan dianalisis. Kemudian, data-data yang dikumpulkan dari hasil kuesioner akan dimasukkan ke dalam garis kontinum atau jumlah skor dimasukan ke dalam garis kontinum yang pengukurannya ditentukan dengan cara sebagai berikut. 
- Nilai Maksimam :Skor/skala Tertinggi x Jumlah Soal/Item Pernyataan x Jumlah Responden

- Nilai Minimum : Skor/Skala Terendah x Jumlah Soal/Item Pernyataan x Jumlah Sampel

- Jarak Interval : (Nilai Maksimum - Nilai Minimum) : Jumlah Skala

- Persentase Skor: (Total Skor : Nilai Maksimal) x 100

Setelah itu, dibuat garis kontinum untuk mengetahui skor yang diperoleh dan disimpulkan. Contoh penghitungan mengenai hal itu mengacu pada hasil perhitungan "Sikap Masyarakat terhadap Rencana Pembangunan Bandara Internasional Jawa Barat (BIJB)” yang kemudian diterapkan pada analisis hasil.

\section{PEMBAHASAN}

\section{a. Frekuensi dan Persentase Bahasa Daerah yang Dituturkan}

Suku bangsa yang berdomisili secara turun temurun, termasuk suku pendatang, di Provinsi Maluku Utara dan Papua Barat sangat beragam sehingga beragam pula bahasa daerah yang dituturkan oleh generasi mudanya. Jika hal itu dikaitkan dengan penuturan bahasa suku/daerah, nama bahasa daerah yang dituturkan generasi muda Maluku Utara dan Papua Barat cukup beragam sesuai nama etniknya (lihat Tabel 1). Frekuensi dan persentase bahasa daerah yang dituturkan oleh mereka diperlihatkan pada Tabel 1 dan 2 berikut.

Tabel 1.

Frekuensi dan Persentase Bahasa Daerah yang Dituturkan oleh Generasi Muda Provinsi Maluku Utara

\begin{tabular}{llll}
\hline No. & Nama Bahasa Daerah & F & \% \\
\hline 1 & Ternate & 50 & 31,3 \\
\hline 2 & Tidore & 29 & 18,1 \\
\hline 3 & Makian Tahane & 26 & 16,3 \\
\hline 4 & Sula & 11 & 6,9 \\
\hline 5 & Melayu & 11 & 6,9 \\
\hline 6 & Galela & 7 & 4,4 \\
\hline 7 & Buton & 4 & 2,5 \\
\hline 8 & Buli & 3 & 1,18 \\
\hline 9 & Loloda & 2 & 1,3 \\
\hline 10 & Sawai & 2 & 1,3 \\
\hline 11 & Kayoa & 1 & 0,6 \\
\hline 12 & Weda & 1 & 0,6 \\
\hline 13 & Maba & 1 & 0,6 \\
\hline 14 & Patani & 1 & 0,6 \\
\hline 15 & Wayoli & 1 & 0,6 \\
\hline 16 & Gamkowora & 1 & 0,6 \\
\hline 17 & Buli & 1 & 0,6 \\
\hline 18 & Tidak menjawab & 10 & 6,4 \\
\hline Total & $\mathbf{1 6 0}$ & $\mathbf{1 0 0}$ \\
\hline
\end{tabular}

Sumber: Diolah dari data primer, 2020 
Tabel 2.

Frekuensi dan Persentase Bahasa Daerah yang Dituturkan oleh Generasi Muda Provinsi Provinsi Papua Barat

\begin{tabular}{llll}
\hline No. & Nama Bahasa Daerah & $\mathbf{F}$ & $\mathbf{\%}$ \\
\hline 1 & Melayu Papua & 28 & 23,3 \\
\hline 2 & Biak (Kebar) (Numfor) & 21 & 17,5 \\
\hline 3 & Hatam (Atam) & 6 & 5 \\
\hline 4 & Sough & 5 & 4,2 \\
\hline 5 & Toraja & 5 & 4,2 \\
\hline 6 & Manyan & 4 & 3,3 \\
\hline 7 & Meyah & 4 & 3,3 \\
\hline 8 & Serui & 4 & 3,3 \\
\hline 9 & Lany & 3 & 2,5 \\
\hline 10 & Waondamen (Wamesa) & 3 & 2,5 \\
\hline 11 & Yali & 3 & 2,5 \\
\hline 12 & Ayamaru & 2 & 1,7 \\
\hline 13 & Bugis & 2 & 1,7 \\
\hline 14 & Irarutu & 2 & 1,7 \\
\hline 15 & Meck & 2 & 1,7 \\
\hline 16 & Batak Toba & 1 & 0,8 \\
\hline 17 & Hubla & 1 & 0,8 \\
\hline 18 & Jawa & 1 & 0,8 \\
\hline 19 & Korowai & 1 & 0,8 \\
\hline 20 & Makassar & 1 & 0,8 \\
\hline 21 & Manggarai & 1 & 0,8 \\
\hline 22 & Melayu Ambon & 1 & 0,8 \\
\hline 23 & Menado & 1 & 0,8 \\
\hline 24 & Moi & 1 & 0,8 \\
\hline 25 & Mongondow & 1 & 0,8 \\
\hline 26 & Muyu & 1 & 0,8 \\
\hline 27 & Ngalik (Yahokimo) & 1 & 0,8 \\
\hline 28 & Ngalum & 1 & 0,8 \\
\hline 29 & Tambraw & 1 & 0,8 \\
\hline 30 & Melayu Ternate & 1 & 0,8 \\
\hline 31 & Wondama & 10 & 8,3 \\
\hline 32 & Tidak menjawab & $\mathbf{1 0 0}$ \\
\hline Total & Sumber: Diolah dari data primer, \\
\hline
\end{tabular}

Tabel 1 menunjukkan bahwa terdapat 18 bahasa daerah yang dituturkan oleh generasi muda Maluku Utara. Mereka mayoritas menuturkan bahasa Sula dengan frekuensi dan persentase sebesar $50(31,3 \%)$ yang diisusul dengan penuturan bahasa Tidore dengan frekuensi dan persentase sebesar 28 (18,1\%); bahasa Makian Tahane 26 (16,3\%); bahasa Sula dan Melayu Ternate dengan masing-masing 11 (6,9\%); bahasa Galela 7 (4,4\%); bahasa Buton 4 (2,5\%); bahasa Buli 3 (1,18\%); bahasa Loloda dan Sawai dengan masing-masing 2 (1,3\%); dan terendah adalah bahasa Kayoa, Weda, Maba, Patani, Wayoli, Gamkowora, dan Buli dengan masingmasing frekuensi dan persentase sebesar $1(0,6 \%)$. Selain itu, $10(6,4 \%)$ di antara mereka tidak menjawab bahasa daerah yang dikuasai. 
Tabel 2 menunjukkan bahwa terdapat 32 jenis bahasa daerah yang dituturkan generasi muda Papua Barat. Mereka mayoritas menuturkan bahasa Melayu Papua dengan frekuensi dan persentase $28(23,3 \%)$ yang disusul dengan penuturan bahasa Biak (Kebar) (Numfor) dengan frekuensi dan persentase 21 (17,5\%); bahasa Hatam dengan frekuensi dan persentse $6(5 \%)$; bahasa Sough dan Toraja dengan masing-masing frekuensi dan persentase 5 (4,2\%); bahasa Manyan, Meyah, dan Serui dengan masing-masing frekuensi dan persentse 2 (2,5\%); bahasa Lany, Waondamen (Wamesa), dan Yali dengan masing-masing frekuensi dan persentase 3 (2,5\%); bahasa Ayamaru, Bugis, Irarutu, dan Meck dengan masing-masing frekuensi dan persentase 2 (1,7\%); dan terendah adalah bahasa Batak Toba, Hubla, Jawa, Jayapura, Korowai, Makassar, Manggarai, Melayu Ambon, Menado, Moi, Mongondow, Muyu, Ngalik (Yahokimo),Ngalum, Tambraw, Melayu Ternate, dan Wondama dengan masing frekuensi dan persentase $1(0,8 \%)$. Selain itu, $10(8,3 \%)$ di antara tidak menjawab bahasa daerah yang dikuasai (lihat Tabel 2).

\section{b. Frekuensi dan Persentase Penguasaan Bahasa Daerah Berdasarkan Ciri Responden}

Frekuensi dan persentase tertinggi bahasa daerah yang dikuasai oleh generasi muda Povinsi Maluku Utara berdasarkan ciri responden pada Tabel 3 dengan kategori sangat baik adalah 34 (21,3\%), cukup baik 82 (51,2\%), tidak baik 41 (25,6\%), dan tidak menjawab 3 $(1,9 \%)$. Sementara itu, frekuensi dan persentase penggunaan bahasa daerah generasi muda Papua Barat berdasarkan ciri responden pada Tabel 4 dengan kategori sangat baik adalah 60 (50\%), cukup baik 31 (25,6\%), dan tidak baik 18 (15\%), dan tidak menjawab 11 (9,2\%).

Tabel 3.

Frekuensi dan Persentase Kategori Penguasaan Generasi Muda Maluku Utara Berdasarkan Ciri Responden

\begin{tabular}{|c|c|c|}
\hline Kategori Penguasaan & $\mathbf{F}$ & $\%$ \\
\hline Tidak menjawab & 3 & 1,9 \\
\hline Sangat baik & 34 & 21,3 \\
\hline Cukup baik & 82 & 51,2 \\
\hline Tidak baik & 41 & 25,6 \\
\hline Total & 160 & 100 \\
\hline
\end{tabular}

Sumber: Diolah dari data primer, 2020

Tabel 4.

Frekuensi dan Persentase Kategori Penguasaan Generasi Muda Papua Barat Berdasarkan Ciri Responden

\begin{tabular}{|c|c|c|}
\hline Kategori Penguasaan & $\mathbf{F}$ & $\%$ \\
\hline Tidak menjawab & 11 & 9,2 \\
\hline Sangat baik & 60 & 50 \\
\hline Cukup baik & 31 & 25,8 \\
\hline Tidak baik & 18 & 15 \\
\hline Total & 120 & 100 \\
\hline
\end{tabular}

Sumber: Diolah dari data primer, 2020 


\section{c. Kategori Penggunaan Bahasa Daerah Generasi Muda Maluku Utara dalam Ranah Keluarga ketika Menulis Surat kepada Mitra Tutur}

Tabel 5 menunjukkan bahwa generasi muda Maluku Utara sebanyak 70,6\% cenderung tidak pernah menggunakan bahasa daerah kepada orang tua; $73,1 \%$ cenderung tidak pernah menggunakan bahasa daerah kepada paman/tante/bibi; 76,3\% cenderung tidak pernah menggunakan bahasa daerah kepada kakek/nenek; 71,9\% cenderung tidak pernah menggunakan bahasa daerah kepada saudara (kakak/adik), dan cenderung tidak pernah menggunakan bahasa daerah kepada $70 \%$ famili jauh.

Tabel 5.

Persentase Penggunaan Bahasa Daerah Generasi Muda Maluku Utara dalam Ranah Keluarga ketika Menulis Surat kepada Mitra Tutur

\begin{tabular}{|c|c|c|c|c|c|c|c|c|c|}
\hline \multirow{2}{*}{ No. } & \multirow{2}{*}{ IP } & \multirow{2}{*}{ Mitra Tutur } & \multicolumn{6}{|c|}{ Alternatif Jawaban dalam \% } & \multirow{2}{*}{ Total } \\
\hline & & & Sel & Ser & Jar & Per & Tiper & Timen & \\
\hline 1 & B7 & Orang tua & 5,6 & 3,1 & 13,8 & 6,9 & 70,6 & - & 100 \\
\hline 4 & B9 & Paman/tante/bibi & 4,4 & 3,1 & 14,4 & 5 & 73,1 & - & 100 \\
\hline 6 & B11 & Kakek/nenek & 3,8 & 3,1 & 10 & 6,9 & 76,3 & - & 100 \\
\hline 3 & B13 & Saudara (kakak/adik) & 5 & 6,3 & 10,6 & 6,3 & 71,9 & - & 100 \\
\hline 5 & B16 & Famili jauh & 5 & 1,9 & 13,1 & 7,5 & 70 & 2,5 & 100 \\
\hline \multicolumn{3}{|c|}{$\%$ Total kecenderunagn } & 23,8 & 17,5 & 61,9 & 32,6 & 361,9 & 2,5 & \\
\hline
\end{tabular}

Sumber: Diolah dari data primer, 2020

Tabel 6.

Frekuensi Penggunaan Bahasa Daerah Generasi Muda Maluku Utara dalam Ranah Keluarga ketika Menulis Surat kepada Mitra Tutur

\begin{tabular}{|c|c|c|c|c|c|c|c|c|}
\hline \multirow{2}{*}{ No. } & \multirow{2}{*}{ IP } & \multirow{2}{*}{ Mitra Tutur } & \multicolumn{5}{|c|}{ Alternatif Jawaban dalam Frekuensi } & \multirow{2}{*}{$\begin{array}{l}\text { Skor } \\
\text { wi.fi }\end{array}$} \\
\hline & & & 5 & 4 & 3 & 2 & 1 & \\
\hline 1 & B7 & Orang tua & 9 & 5 & 22 & 11 & 113 & \\
\hline 2 & B9 & Paman/tante/bibi & 7 & 5 & 23 & 8 & 117 & \\
\hline 3 & $\mathrm{~B} 11$ & Kakek/nenek & 6 & 5 & 16 & 11 & 122 & \\
\hline 4 & B13 & Saudara (kakak/adik) & 8 & 10 & 17 & 10 & 115 & \\
\hline \multirow[t]{3}{*}{5} & B16 & Famili jauh & 8 & 3 & 21 & 12 & 112 & \\
\hline & & Total fi & 43 & 32 & 102 & 54 & 580 & \\
\hline & & Skor wi.fi & 215 & 128 & 306 & 108 & 580 & 1337 \\
\hline
\end{tabular}

Sumber: Diolah dari data primer, 2020

Penggunaan bahasa daerah generasi muda Maluku Utara dalam ranah keluarga ketika menulis surat kepada mitra tutur dapat dikategorikan berdasarkan garis kontinum. Pada Tabel 6 terdapat 160 responden, 5 item pernyataan, 5 jumlah skala, dan total skor 1337. Rangkaian angka tersebut divisualisasi ke dalam garis kontinum dengan cara penghitungan berikut.

a. Jumlah responden adalah 160 orang; jumlah pertanyaan 5; jumlah skala 5; dan total skor 1337.

b. Perhitungan (1) nilai maksimum (skala terbesar $\mathrm{x}$ pertanyaan $\mathrm{x}$ responden $=5 \times 5 \times 160=$ 4.000); (2) nilai minimum (skala terkecil $\times$ pertanyaan $\times$ responden $=1 \times 5 \times 160=800$ ); (3) jarak interval ((nilai maksimum - nilai minimum): jumlah skala $=(4.000-800): 5=640)$; (4) persentase skor ((total skor : nilai maksimum) $\times 100 \%=(1.337: 4.000) \times 100 \%=$ $33,42 \%)$; dan (5) garis kontinum sebagai berikut. 


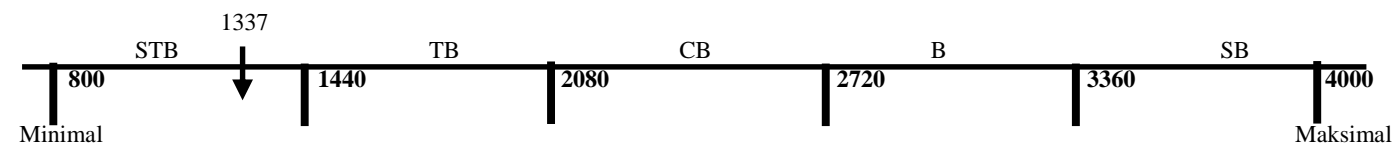

Garis Kontinium 2

Posisi dan Interpretasi Rentang Skala Likert Penggunaan Bahasa Daerah Generasi Muda Maluku Utara dalam Ranah Keluarga ketika Menulis Surat kepada Mitra Tutur

Skor ideal yang diharapkan untuk IP B7, B9, B11, B13, dan B16 adalah 4.000, sedangkan skor total yang diperoleh adalah 1.337. Dari skor total diperoleh persentase skor sebesar 33,42\% dari skor ideal. Dengan demikian, penggunaan bahasa daerah oleh generasi muda Maluku Utara dalam ranah keluarga ketika menulis surat kepada mitra tutur tergolong sangat tidak baik (lihat Garis Kontinium 2).

\section{d. Penggunaan Bahasa Daerah Generasi Muda Maluku Utara dalam Ranah Keluarga ketika Menulis SMS/WA kepada Mitra Tutur}

Persentase penggunaan bahasa daerah oleh generasi muda Maluku Utara dalam ranah keluarga berdasarkan lima item pernyataan ketika menulis SMS/WA kepada saudara (kakak/adik), famili, orang tua, paman/tante/bibi, dan kakek/nenek dapat diketahui berdasarkan Tabel 7. Sementara itu, posisi penggunaannya dalam garis kontinum berdasarkan rentang skala Likert dapat dilihat pada Tabel 8 dan Garis Kontinum 3.

Sesuai dengan Tabel 7, persentase generasi muda Maluku Utara ketika menulis SMS/WA kepada saudara (kakak/adik), famili, orang tua, paman/tante/bibi, dan kakek/nenek menunjukkan bahwa 51,2\% cenderung tidak pernah menggunakan bahasa daerah kepada saudara (kakak/adik), 76,3\% kepada famili, 53,8\% kepada orang tua, 60,6\% kepada paman/tante/bibi, dan 48,8\% kepada kakek/nenek.

Tabel 7.

Persentase Penggunaan Bahasa Daerah Generasi Muda Maluku Utara dalam Ranah Keluarga ketika Menulis SMS/WA kepada Mitra Tutur

\begin{tabular}{|c|c|c|c|c|c|c|c|c|c|}
\hline \multirow[b]{2}{*}{ No. } & \multirow[b]{2}{*}{ IP } & \multirow[b]{2}{*}{ Mitra Tutur } & \multicolumn{6}{|c|}{ Alternatif Jawaban dalam \% } & \multirow[b]{2}{*}{ Total } \\
\hline & & & Sel & Ser & Jar & Per & Tiper & Timen & \\
\hline 1 & B8 & Saudara (kakak/adik) & 8,8 & 13,1 & 16,9 & 10 & 51,2 & - & 100 \\
\hline 2 & B10 & Famili & 4,4 & 16,9 & 15 & 15 & 48,8 & - & 100 \\
\hline 3 & B12 & Orang tua & 10 & 13,1 & 13,1 & 9,4 & 53,8 & 0,6 & 100 \\
\hline 4 & B14 & Paman/tante/bibi & 5,6 & 7,5 & 13,1 & 13,1 & 60,6 & - & 100 \\
\hline 5 & B15 & Kakek/nenek & 4,4 & 16,9 & 15 & 15 & 48,8 & - & 100 \\
\hline
\end{tabular}

Sumber: Diolah dari data primer, 2020 
Tabel 8.

Frekuensi Penggunaan Bahasa Daerah Generasi Muda Maluku Utara dalam Ranah Keluarga ketika Menulis SMS/WA kepada Mitra Tutur Penggunaan Bahasa Daerah

\begin{tabular}{|c|c|c|c|c|c|c|c|c|}
\hline \multirow[b]{2}{*}{ No. } & \multirow[b]{2}{*}{ IP } & \multirow[b]{2}{*}{ Mitra Tutur } & \multicolumn{5}{|c|}{ Alternatif Jawaban dalam Frekuensi } & \multirow{2}{*}{$\begin{array}{l}\text { Skor } \\
\text { wi.fi }\end{array}$} \\
\hline & & & 5 & 4 & 3 & 2 & 1 & \\
\hline 1 & B8 & Saudara (kakak/adik) & 14 & 21 & 27 & 16 & 82 & \\
\hline 2 & B10 & Famili & 7 & 23 & 35 & 18 & 77 & \\
\hline 3 & $\mathrm{~B} 12$ & Orang tua & 16 & 21 & 21 & 15 & 86 & \\
\hline 4 & B14 & Paman/tante/bibi & 9 & 12 & 21 & 21 & 97 & \\
\hline \multirow[t]{3}{*}{5} & B15 & Kakek/nenek & 7 & 27 & 24 & 24 & 78 & \\
\hline & & Total fi & 58 & 108 & 131 & 96 & 421 & \\
\hline & & Skor wi.fi & 290 & 432 & 393 & 192 & 421 & 1728 \\
\hline
\end{tabular}

Penggunaan bahasa daerah generasi muda Maluku Utara dalam ranah keluarga ketika menulis SMS/WA kepada mitra tutur dapat dikategorikan berdasarkan garis kontinum. Pada Tabel 8 terdapat 160 responden, 5 item pernyataan, 5 jumlah skala, dan total skor 1728 . Rangkaian angka itu divisualisasi ke dalam garis kontinum dengan cara penghitungan berikut.

a. (1) jumlah responden adalah 160 orang; (2) jumlah pertanyaan 5; (3) jumlah skala 5; dan (4) total skor 1728.

b. Perhitungan (1) nilai maksimum (skala terbesar x pertanyaan $\mathrm{x}$ responden $=5 \times 5 \times 160=$ 4.000); (2) nilai minimum (skala terkecil x pertanyaan $\mathrm{x}$ responden $=1 \times 5 \times 160=800$ ); (3) jarak interval ((nilai maksimum - nilai minimum): jumlah skala $=(4.000-800): 5$; 640; (4) persentase skor ((total skor : nilai maksimum) $\times 100 \%=(1.728: 4.000) \times 100 \%=$ 43,2\%); dan (5) garis kontinum sebagai berikut.

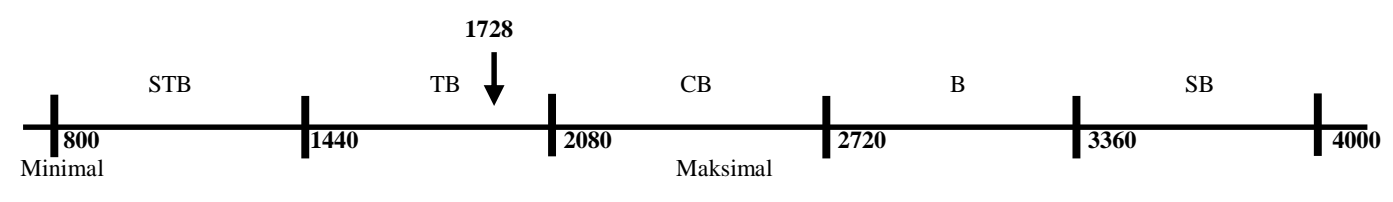

Garis Kontinium 3

Posisi dan Interpretasi Rentang Skala Likert Penggunaan Bahasa Daerah Generasi Muda Provinsi Maluku Utara dalam Ranah Keluarga ketika Menulis SMS/WA kepada Mitra Tutur

Skor ideal yang diharapkan untuk IP B8, B10, B12, B14, dan B15 adalah 4.000. Skor total yang diperoleh adalah 1.728 dengan persentase skor adalah 43,2\% dari skor ideal. Dengan demikian, penggunaan bahasa daerah oleh generasi muda Maluku Utara dalam ranah keluarga ketika menulis SMS/WA kepada mitra tutur tergolong tidak baik (lihat Garis Kontinium 3). 


\section{e. Kategori Penggunaan Bahasa Daerah Generasi Muda Papua Barat dalam Ranah Keluarga ketika Menulis Surat kepada Mitra Tutur}

Tabel 8 menunjukkan bahwa generasi muda Papua Barat sebesar 52,5\% cenderung tidak pernah menggunakan bahasa daerah ketika menulis surat kepada orang tua, 51,7\% cenderung tidak pernah menggunakan bahasa daerah ketika menulis surat kepada kakak/adik, 55,8\% cenderung tidak pernah menggunakan bahasa daerah ketika menulis surat kepada bibi/paman, $62,5 \%$ cenderung tidak pernah menggunakan bahasa daerah ketika menulis tidak pernah menggunakan bahasa daerah ketika menulis surat kepada kakek/nenek, dan $60 \%$ cenderung tidak pernah menggunakan bahasa daerah ketika menulis surat kepada kerabat.

Tabel 9.

Persentase Penggunaan Bahasa Daerah Generasi Muda Papua Barat dalam Ranah Keluarga ketika Menulis Surat kepada Mitra Tutur

\begin{tabular}{|c|c|c|c|c|c|c|c|c|c|}
\hline \multirow{2}{*}{ No. } & \multirow{2}{*}{ IP } & \multirow{2}{*}{ Mitra Tutur } & \multicolumn{6}{|c|}{ Alternatif Jawaban dalam \% } & \multirow{2}{*}{ Total } \\
\hline & & & Sel & Ser & Jar & Per & Tiper & Timen & \\
\hline 1 & B2.a & Surat kepada orang tua. & 20,8 & Ser & 9,2 & 5 & 52,5 & 0,8 & 100 \\
\hline 4 & B2.b & Surat kepada kakak/adik. & 20,8 & 11,7 & 10,8 & 6,7 & 51,7 & 0,8 & 100 \\
\hline 6 & B2.c & Surat kepada bibi/paman. & 16,7 & 9,2 & 14,2 & 2,5 & 55,8 & 0,8 & 100 \\
\hline 3 & B2.d & Surat kepada kakek/nenek & 15,8 & 10 & 12,5 & 1,7 & 62,5 & 0,8 & 100 \\
\hline \multirow[t]{2}{*}{5} & B2.e & Surat kepada kerabat. & 15 & 6,7 & 12,5 & 6,7 & 60 & 0,8 & 100 \\
\hline & & \% Total kecenderunagn & 89,1 & 42,6 & 59,2 & 22,6 & 282,5 & 4 & \\
\hline
\end{tabular}

Sumber: Diolah dari data primer, 2020

Tabel 10 .

Frekuensi Penggunaan Bahasa Daerah Generasi Muda Papua Barat dalam Ranah Keluarga ketika Menulis Surat kepada Mitra Tutur

\begin{tabular}{|c|c|c|c|c|c|c|c|c|}
\hline \multirow{2}{*}{ No. } & \multirow{2}{*}{ IP } & \multirow{2}{*}{ Mitra Tutur } & \multicolumn{5}{|c|}{ Alternatif Jawaban dalam Frekuensi } & \multirow{2}{*}{$\begin{array}{l}\text { Skor } \\
\text { wi.fi }\end{array}$} \\
\hline & & & 5 & 4 & 3 & 2 & 1 & \\
\hline 1 & B2.a & Surat kepada orang tua. & 32 & 10 & 9 & 12 & 56 & \\
\hline 2 & B2.b & Surat kepada kakak/adik. & 36 & 10 & 9 & 18 & 47 & \\
\hline 3 & B2.c & Surat kepada bibi/paman. & 28 & 11 & 11 & 11 & 59 & \\
\hline 4 & B2.d & Surat kepada kakek/nenek & 25 & 10 & 6 & 7 & 71 & \\
\hline \multirow[t]{3}{*}{5} & B2.e & Surat kepada kerabat. & 33 & 10 & 8 & 12 & 56 & \\
\hline & & Total fi & 154 & 51 & 43 & 60 & 289 & \\
\hline & & Skor wi.fi & 770 & 204 & 129 & 120 & 289 & 1512 \\
\hline
\end{tabular}

Sumber: Diolah dari data primer, 2020

Penggunaan bahasa daerah generasi muda Papua Barat dalam ranah keluarga ketika menulis surat kepada mitra tutur dapat dikategorikan berdasarkan garis kontinum. Pada Tabel 10 terdapat 160 responden, 5 item pernyataan, 5 jumlah skala, dan total skor 1.512 . Rangkaian angka tersebut divisualisasi ke dalam garis kontinum dengan cara penghitungan berikut.

a. (1) Jumlah responden adalah 160 orang; (2) jumlah pertanyaan 5; (3) jumlah skala 5; dan (4) total skor 1.512 .

b. Penghitungan (1) nilai maksimum (skala terbesar $\mathrm{x}$ pertanyaan $\mathrm{x}$ responden $=5 \times 5 \times 160=$ 4000); (2) nilai minimum (skala terkecil x pertanyaan x responden $=1 \times 5 \times 160=800$ ); (3) jarak interval ((nilai maksimum - nilai minimum): jumlah skala $=(4.000-800): 5=640)$; 
(4) persentase skor ((total skor : nilai maksimum) x 100\% $=(1.512: 4.000 \times 100 \%=37,8 \%)$; dan (5) garis kontinum sebagai berikut.

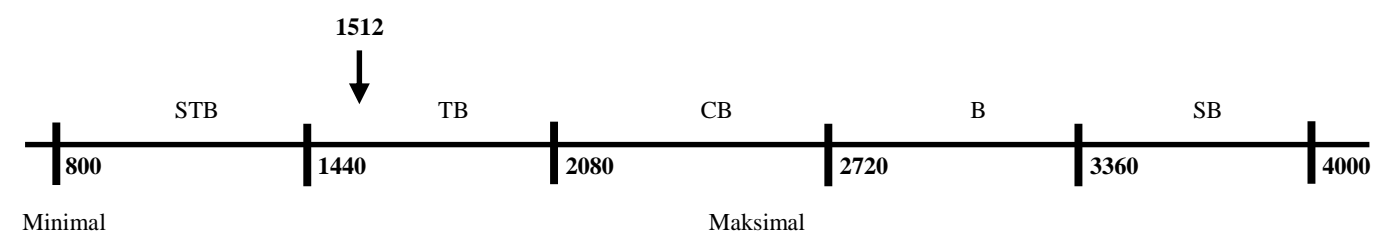

Garis Kontinium 4

Posisi dan Interpretasi Rentang Skala Likert Penggunaan Bahasa Daerah Generasi Muda Papua Barat dalam Ranah Keluarga ketika Menulis Surat kepada Mitra Tutur

Skor ideal yang diharapkan untuk IP B2.a-B2.e adalah 4.000. Skor total yang diperoleh adalah 1.512 dengan persentase skor adalah 37,8\% dari skor ideal. Dengan demikian, penggunaan bahasa daerah oleh generasi muda Papua Barat dalam ranah keluarga ketika menulis surat kepada mitra tutur tergolong tidak baik (lihat Garis Kontinium 4).

\section{f. Kategori Penggunaan Bahasa Daerah Generasi Muda Papua Barat dalam Ranah Keluarga ketika Menulis SMS/WA kepada Mitra Tutur}

Tabel 11 menunjukkan bahwa generasi muda Papua Barat sebesar 46,7 \% cenderung tidak pernah menggunakan bahasa daerah ketika menulis SMS/WA kepada orang tua, 39,2 \% cenderung tidak pernah menggunakan bahasa daerah ketika menulis SMS/WA kepada kakak/adik, 49,2 \% cenderung tidak pernah menggunakan bahasa daerah ketika menulis SMS/WA kepada bibi/paman, 59,2 \% cenderung tidak pernah menggunakan bahasa daerah ketika menulis SMS/WA kepada kakek/nenek, dan 46,7 \% cenderung tidak pernah menggunakan bahasa daerah ketika menulis SMS/WA kepada kerabat.

Tabel 11.

Persentase Penggunaan Bahasa Daerah Generasi Muda Papua Barat dalam Ranah Keluarga ketika Menulis SMS/WA kepada Mitra Tutur

\begin{tabular}{|c|c|c|c|c|c|c|c|c|c|}
\hline \multirow{2}{*}{ No. } & \multirow{2}{*}{ IP } & \multirow{2}{*}{ Mitra Tutur } & \multicolumn{6}{|c|}{ Alternatif Jawaban dalam \% } & \multirow{2}{*}{ Total } \\
\hline & & & Sel & Ser & Jar & Per & Tiper & Timen & \\
\hline 1 & B2.f & SMS/WA kepada orang tua. & 26,7 & 8,3 & 7,5 & 10 & 46,7 & 0,8 & 100 \\
\hline 4 & B2.g & SMS/WA kepada kakak/adik. & 30 & 8,3 & 7,5 & 15 & 39,2 & 0 & 100 \\
\hline 6 & B2.h & SMS/WA kepada bibi/paman. & 23,3 & 9,2 & 9,2 & 9,2 & 49,2 & 0 & 100 \\
\hline 3 & B2.i & Menulis SMS/WA kepada kakek/nenek. & 20,8 & 8,3 & 5 & 5,8 & 59,2 & 0,8 & 100 \\
\hline \multirow[t]{2}{*}{5} & B2.j & SMS/WA kepada kerabat. & 27,5 & 8,3 & 6,7 & 10 & 46,7 & 0,8 & 100 \\
\hline & & \% Total kecenderunagn & 128,3 & 42,4 & 35,9 & 50 & 241 & 2,4 & \\
\hline
\end{tabular}

Sumber: Diolah dari data primer, 2020 
Tabel 12.

Frekuensi Penggunaan Bahasa Daerah Generasi Muda Papua Barat dalam Ranah Keluarga ketika Menulis SMS/WA kepada Mitra Tutur

\begin{tabular}{|c|c|c|c|c|c|c|c|c|}
\hline \multirow{2}{*}{ No. } & \multirow{2}{*}{ IP } & \multirow{2}{*}{ Mitra Tutur } & \multicolumn{5}{|c|}{ Alternatif Jawaban dalam Frekuensi } & \multirow{2}{*}{$\begin{array}{l}\text { Skor } \\
\text { wi.fi }\end{array}$} \\
\hline & & & 5 & 4 & 3 & 2 & 1 & \\
\hline 1 & B2.f & SMS/WA kepada orang tua. & 32 & 10 & 9 & 56 & 1 & \\
\hline 2 & B2.g & SMS/WA kepada kakak/adik. & 36 & 10 & 9 & 47 & $\mathbf{0}$ & \\
\hline 3 & B2.h & SMS/WA kepada bibi/paman. & 28 & 11 & 11 & 59 & $\mathbf{0}$ & \\
\hline 4 & B2.i & Menulis SMS/WA kepada kakek/nenek. & 25 & 10 & 6 & 71 & 1 & \\
\hline \multirow[t]{3}{*}{5} & B2.j & SMS/WA kepada kerabat. & 33 & 10 & 8 & 56 & 1 & \\
\hline & & Total fi & 154 & 51 & 43 & 289 & 3 & \\
\hline & & Skor wi.fi & 770 & 204 & 129 & 578 & 3 & 1684 \\
\hline
\end{tabular}

Sumber: Diolah dari data primer, 2020

Penggunaan bahasa daerah generasi muda Papua Barat dalam ranah keluarga ketika menulis surat kepada mitra tutur dapat dikategorikan berdasarkan garis kontinum. Pada Tabel 12 terdapat 160 responden, 5 item pernyataan, 5 jumlah skala, dan total skor 1648. Rangkaian angka tersebut divisualisasi ke dalam garis kontinum dengan cara penghitungan berikut.

a. (1) Jumlah responden adalah 160 orang; (2) jumlah pertanyaan = 5; (3) jumlah skala 5; dan (4) total skor 1.684.

b. Penghitungan (1) nilai maksimum (skala terbesar x pertanyaan $\mathrm{x}$ responden $=5 \times 5 \times 160=$ 4.000); (2) nilai minimum $=$ skala terkecil $\times$ pertanyaan $\times$ responden $=1 \times 5 \times 160=800$; (3) jarak interval ((nilai maksimum - nilai minimum): jumlah skala $(4.000-800): 5=640$; (4) persentase skor (total skor : nilai maksimum) $\times 100 \%=(1.684: 4.000) \times 100 \%=42,1 \%$; dan (5) garis kontinum sebagai berikut.

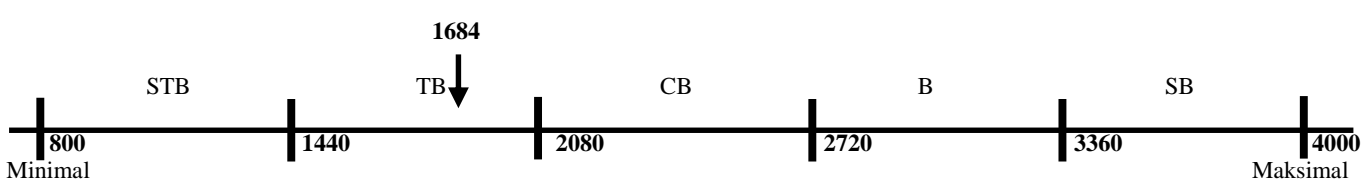

Garis Kontinum 5

Posisi dan Interpretasi Rentang Skala Likert Penggunaan Bahasa Daerah dalam Ranah Keluarga ketika Menulis Surat kepada Mitra Tutur (Keluarga)

Skor ideal yang diharapkan untuk IP B2.F-B2.J adalah 4.000. Skor total yang diperoleh adalah 1.684 dengan persentase skor adalah 42,3\% dari skor ideal. Dengan demikian, penggunaan bahasa daerah oleh generasi muda Papua Barat dalam ranah keluarga ketika menulis surat kepada mitra tutur tergolong tidak baik (lihat Garis Kontinium 5).

\section{Pembahasan Umum}

Kedelapan belas jenis bahasa daerah yang dituturkan generasi muda Maluku Utara pada Tabel 1 sudah termasuk bahasa daerah yang dituturkan oleh generasi muda pendatang. Salah satu bahasa etnik generasi muda Maluku Utara pendatang adalah bahasa Buton, sedangkan 16 
bahasa daerah lainnya adalah bahasa daerah asli yang dituturkan di Provinsi Maluku Utara (Sunendar, 2018, pp. 180--185).

Hal yang sama terjadi juga dengan ke-34 bahasa daerah yang dituturkan generasi muda Papua Barat pada Tabel 2 yang sudah termasuk bahasa daerah yang diituturkan oleh generasi muda pendatang. Sembilan bahasa daerah di antaranya merupakan bahasa daerah generasi muda pendatang Provinsi Papua seperti bahasa Biak (Kebar) (Numfor), Serui, Lany, Yali, Korowai, Moi, Muyu, Ngalik (Yahokimo), dan Ngalum; tiga bahasa daerah dari generasi muda pendatang Provinsi Sulawesi Utara seperti bahasa Toraja, Menado, dan Mongondow; dua bahasa daerah dari generasi muda pendatang Provinsi Sulawesi Selatan, yaitu bahasa Bugis dan Makassar; satu bahasa daerah dari generasi muda pendatang Provinsi Sumatera Utara, yaitu bahasa Batak Toba; satu bahasa daerah dari generasi muda pendatang Provinsi Nusa Tenggara Timur, yaitu bahasa Manggarai; satu bahasa daerah dari generasi muda pendatang Provinsi Maluku, yaitu bahasa Melayu Ambon; dan satu bahasa daerah dari generasi muda pendatang Provinsi Maluku Utara, yaitu bahasa Melayu Ternate. Dengan demikian, bahasa daerah asli generasi muda Provinsi Papua Barat pada Tabel 2 hanya terdiri atas sebelas daerah (Sunendar, 2018, hal. 257--282).

Responden generasi muda Papua Barat yang memiliki kemampuan bahasa daerah dengan kategori sangat baik berjumlah lebih banyak dibandingkan dengan responden generasi muda di Maluku Utara. Sementara itu, generasi muda Maluku Utara yang memiliki kemampuan bahasa daerah kategori cukup baik berjumlah lebih banyak dibandingkan dengan generasi muda Papua Barat. Begitu pula dengan generasi muda Maluku Utara yang kemampuan bahasa daerah kategori tidak baik berjumlah lebih banyak dibandingkan dengan generasi muda Papua Barat.

Kategori penggunaan bahasa daerah generasi muda Maluku Utara dalam ranah keluarga ketika menulis surat kepada mitra tutur (orang tua, paman/tante/bibi, kakek/nenek, saudara (kakak/adik), dan famili jauh) tergolong sangat tidak baik, sedangkan generasi muda Papua Barat tergolong tidak baik. Kategori penggunaan bahasa daerah generasi muda Maluku Utara dan Papua Barat dalam ranah keluarga ketika menulis SMS/WA kepada mitra tutur (orang tua, paman/tante/bibi, kakek/nenek, saudara (kakak/adik), dan famili jauh) sama-sama tergolong tidak baik. Pengategorian penggunaan bahasa daerah seperti itu didasarkan pada keterbatasan pemilikan media penyampaiannya, baik akibat keterbatasan pemilikan telepon genggam di kalangan generasi muda Maluku Utara dan Papua Barat maupun di kalangan mitra tutur generasi muda Maluku Utara dan Papua Barat. 


\section{PENUTUP}

Identitas keetnisan generasi muda Maluku Utara dan Papau Barat cukup beragam. Keberagaman itu menyebabkan keberagaman bahasa daerah yang dituturkan oleh generasi muda di kedua wilayah itu. Bahasa-bahasa daerah yang digunakan oleh kedua kelompok pemuda itu dalam aktivitas menulis dengan mitra tutur dalam ranah keluarga kurang produktif. Generasi muda Maluku Utara menulis surat kepada mitra tutur (orang tua, paman/tante/bibi, kakek/nenek, saudara (kakak/adik), dan famili jauh) dengan bahasa daerah melalui surat tergolong sangat tidak baik dan melalui SMS/WA tergolong tidak baik. Generasi muda Papua Barat menulis surat kepada mitra tutur (orang tua, paman/tante/bibi, kakek/nenek, saudara (kakak/adik), dan famili jauh) dengan bahasa daerah, baik melalui surat maupun SMS/WA tergolong tidak baik.

\section{DAFTAR PUSTAKA}

Amelia, M. (2016). Gaya Bahasa Mahasiswa dalam Meminta Izin melalui SMS dan Respon Dosen. Lingua Didaktika Volume. 9(1), 37-45. https://doi.org/10.1017/CBO9781107415324.004

Baru, Y. (2018). Sistem Numeralia Bahasa Miyah. Jurnal Ilmiah Kajian Bahasa dan Sastra, 1(1), 77. https://doi.org/10.30862/jm.v1i1.739

Chaer, A. (2010). Sosiolinguistik Perkenalan Awal. Jakarta: PT Rineka Cipta.

Chaer, A. dan L. A. (2004). Sosiolinguistik. Jakarta: Rineka Cipta.

Damanik, R. (2009). Pemertahanan Bahasa Simalungun di Kabupaten Simalungun. Tesis. Medan: Universitas Sumatera Utara.

Durianto, D. et al. (2003). Invasi Pasar dengan Iklan yang Efektif. Jakarta, PT Gramedia Pustaka Utama.

Ibrahim, G. A. (2011). Bahasa Terancam Punah: Fakta, Sebab-Musabab, Gejala, dan Strategi Perawatannya. Linguistik Indonesia, 29(1), 35-52. https://www.google.co.id/search?q=Bahasa+Terancam+Punah\%3A+Fakta\%2C+SebabMusabab\%2C+Gejala\%2C+dan+Stra tegi+Perawatannya+Gufran\&rlz=1C1CHWL_enID780ID780\&oq=Bahasa+Terancam+ Punah\%3A+Fakta\%2C+SebabMusabab\%2C+Gejala\%2C+dan+Strategi+Perawatannya + Gufran\&aqs $=\mathrm{c}$

Karim, K. H., \& Hasim, R. (2018). Pengunaan Bahasa Ternate dalam Sastra Lisan dan Acara Ritual Keagamaan. Jurnal Ilmu Budaya, 6(1), 166-175. https://doi.org/10.34050/jib.v6i1.4321

Kridalaksana, H. (2009). Kamus Linguistik. Jakarta: PT Gramedia Pustaka Utama.

Maturbongs, A., \& Asmabuasappe, A. (2016). Fonologi Bahasa Abun Di Kabupaten Tambrauw Provinsi Papua Barat. Jurnal Pendidikan Bahasa dan Sastra, 16(1), 58. https://doi.org/10.17509/bs_jpbsp.v16i1.3062

Nurjannah, A., \& Suhara, A. M. (2019). Analisis Penggunaan Bahasa Daerah dalam Pembelajaran Menulis Cerpen di Kelas IX SMPN 1 Cipatat Kabupaten Bandung Barat. Parole (Jurnal Pendidikan Bahasa Dan Sastra Indonesia), 2(2), 255-262.

Setiawati, M. A., Nur, D. M., Yani, A., Geografi, D. P., Respon Masyarakat Terhadap Rencana Pembangunan. 1(September), 1-16.

Sudjino, A. (2012). Pengantar Statistik Pendidikan. Jakarta: Raja Grafindo Persada.

Sumarsono. (2007). Sosiolinguistik. Yogyakarta: Sabda dan Pustaka Pelajar. 
Sunendar, Dadang, D. (2018). Bahasa dan Peta Bahasa di Indonesia Edisi Kelima. Jakarta: Badan Pengembangan dan Pembinaan Bahasa, Kementerian Pendidikan dan Kebudayaan.

Wardhaugh, R. (1986). An Introduction to Sociolinguistics. Oxford: Basil Blackwell.

Wardhaugh, R. (2006). An Introduction to Sociolinguistics. Oxford: Basil Blackwell.

Wijana, I. D. P. dan M. R. (2013). Sosiolinguistik: Kajian Teori dan Analisis. Yogyakarta: Pustaka Pelajar. 